\section{Racial Differences in Physical and Mental Health}

\section{Socio-economic Status, Stress and Discrimination}

\author{
DA VID R. WILLIAMS, YAN YU, \& JAMES \\ S. JACKSON \\ University of Michigan, USA
}

NORMAN B. ANDERSON

National Institutes of Health, Office of Behavioral and Social Sciences Research, Bethesda, Maryland, USA

d a vid r. will ia ms (PhD University of Michigan, MPH Loma Linda University) is currently Associate Professor of Sociology and Associate Research Scientist at the Survey Research Center, Institute for Social Research, University of Michigan, USA.

y a n y u (PhD Purdue University, MS Purdue University) is currently a Postdoctoral Fellow at the Survey Research Center, Institute for Social Research, University of Michigan, USA.

ja mes s. ja ck son (PhD Wayne State University, MA University of Toledo) is currently Daniel Katz Distinguished University Professor of Psychology, Director and Research Scientist at the Research Center for Group Dynamics, Institute for Social Research, University of Michigan, USA.

n or ma n b. a n der son (PhD and MA University of North Carolina at Greensboro, BA North Carolina Central University) is currently the Director of the Office of Behavioral and Social Sciences Research, National Institutes of Health, Bethesda, Maryland and Associate Professor of Psychiatry and Psychology, Duke University, USA.

a cknowledgement. Preparation of this article as a paper was supported in part by grant MH 47182 from the National Institute of Mental Health and by a Robert Wood Johnson Foundation Investigator Award in Health Policy Research to David R. Williams.

a d d r e ss. Address correspondence to:

d a vid r . w il 1 ia ms Institute for Social Research, University of Michigan, P.O. Box 1248, Ann Arbor, MI 48106-1248, USA. [email: wildavid@umich.edu]
Journal of Health Psychology Copyright (C) 1997 SAGE Publications London, Thousand Oaks and New Delhi, ISSN: $1359-1053$ Vol 2(3) 335-351

\section{Abstract}

This article examines the extent to which racial differences in socio-economic status (SES), social class and acute and chronic indicators of perceived discrimination, as well as general measures of stress can account for black-white differences in self-reported measures of physical and mental health. The observed racial differences in health were markedly reduced when adjusted for education and especially income. However, both perceived discrimination and more traditional measures of stress are related to health and play an incremental role in accounting for differences between the races in health status. These findings underscore the need for research efforts to identify the complex ways in which economic and non-economic forms of discrimination relate to each other and combine with socio-economic position and other risk factors and resources to affect health.

\section{Keywords}

race, racial bias, social class, socio-economic status, stress 
on e of the most firmly est ablished and frequently reported patterns in the distribution of health status in the United States is that African Americans (or blacks) have higher rates of death, disease and disability than whites have. This pattern has been documented for over 150 years (Krieger, 1987) and in 1990 blacks had higher rates than whites for 13 of the 15 leading causes of death in the United States (National Center for Health Statistics, 1994). Although the findings are not uniform, studies of mental health status also generally find that, compared to whites, blacks have higher levels of psychological distress (nonspecific emotional symptoms) and lower levels of subjective well-being (Vega \& Rumbaut, 1991). Recent data reveal that for some indicators of health status, such as infant mortality and low birth weight, the relative gap between blacks and whites has widened in recent decades, while for other indicators, such as life expectancy and sexually transmitted diseases, there has been an absolute decline in the health of the African-American population in some recent years (Williams \& Collins, 1995).

Despite decades of research, our understanding of the factors responsible for racial differences in health is still limited. Historically, research on racial differences in health has been premised on the notion that blacks and whites were biologically distinct groups and that observed disparities could be traced to biological differences between the races (Krieger, 1987). Much of this research was blatantly racist and explicitly attempted to provide a scientific rationale for policies of racial inequality. Blatant racial bias is rare in current research in the medical sciences, but there is a persistent tendency, even in the face of scientific evidence to the contrary, to define race in terms of underlying genetic homogeneity and to understand racial differences in health in terms of innate biological differences (Williams, Lavizzo-Mourey, \& Warren, 1994; Witzig, 1996). In contrast, anthropologists (Gould, 1977; Lewontin, 1972) and health researchers (Cooper \& David, 1986; Krieger, Rowley, Herman, Avery, \& Phillips, 1993; Williams, in press) emphasize the scientific information that indicates that race is a gross indicator of distinctive social and individual histories and not a measure of biological distinctiveness. Races are socially constructed categories that have emerged in the context of social and economic oppression and have been used to perpetuate economic, cultural, ideological, political and legal systems of inequality (Omi \& Winant, 1986). This view of race does not deny that there may be biological aspects to race. However, genetic or biologic factors are not the central defining characteristics of race and are unlikely to be the primary sources of racial differences in health. Although racial differences in biological processes have been found (e.g. in sodium secretion), these processes may be influenced by psychosocial factors (Anderson, McNeilly, \& Myers, 1991). Moreover, not only can social conditions produce physiological differences between races, they may also interact with any innate biological differences to affect health.

\section{Race, SES and health}

The worsening health status of African Americans must be understood within the larger context of the increasing polarization of income and wealth in the United States. In recent years much of the past gains in economic status of blacks relative to whites has been arrested. For some economic indicators blacks have experienced a decline relative to whites, while others reveal an absolute decline in the economic situation of African Americans (Karoly, 1992; Smith \& Welch, 1989). The United States is not unique. There is growing income inequality in other western industrialized countries (Danziger \& Gottschalk, 1993), and a commensurate widening in socio-economic status (SES) differences in health (Williams \& Collins, 1995).

Given the strong relationship between race and systems of inequality, social and behavioral scientists have emphasized that differences between the races in socio-economic circumstances are centrally responsible for racial variations in health. There are large racial differences in SES. The 1990 Census, for example, indicated that compared to whites, African Americans have a median family income that is 63 percent less, are more than twice as likely to be unemployed, three times as likely to be poor and twice as likely not to have graduated from college (National Center for Health Statistics, 1993). Accordingly, studies of racial differences in health routinely control for SES and it is 
generally found that adjustment for SES substantially reduces and sometimes eliminates racial disparities in health (Krieger et al., 1993; Lillie-Blanton, Parsons, Gayle, \& Dievler, 1996).

Although racial differences are markedly reduced, it is frequently found that they persist even after adjustment for SES (Lillie-Blanton et al., 1996). Moreover, for some indicators of SES, racial differences increase as SES increases (Krieger et al., 1993). Accordingly, several recent critiques have emphasized that the current paradigm of an almost exclusive focus on differences in SES as responsible for racial differences in health is inadequate (Cooper \& David, 1986; Hummer, 1996; Krieger et al., 1993; Williams et al., 1994). First, SES measures are not equivalent across racial groups. That is, there are racial differences in income returns for a given level of education, the quality of education, the level of wealth associated with a given level of income, the purchasing power of income, the stability of employment and the health risks associated with working in particular occupations (Williams \& Collins, 1995). Thus, even when race differences in health are 'explained' by SES, group differences in the very nature of SES make the interpretation of such findings difficult.

Second, it has been emphasized that SES is not just a confounder of the relationship between race and health, but part of the causal pathway by which race affects health (Cooper \& David, 1986). That is, race is an antecedent and determinant of SES, and SES differences between blacks and whites reflect, in part, the impact of economic discrimination as produced by large-scale societal structures. Racial residential segregation is a prime example of a societal structure that importantly restricts socio-economic opportunity and mobility for blacks (Massey \& Denton, 1993). Third, the conceptualization and measurement of SES is limited. SES is too often used in a static, routine and atheoretical manner. Finally, the persistence of racial differences after adjustment for SES emphasizes that race is more than SES and that additional research attention is required to understand the ways in which unique experiences linked to race, such as non-economic forms of racial discrimination can adversely affect health.
At the present time it is unclear whether the failure of SES to account completely for racial differences in health reflects limitations of the measures of SES or the failure of researchers to consider race-related risk factors such as racial discrimination. Enhancing our understanding of the ways in which race and SES combine to affect health will require research initiatives in two directions. First, we need more comprehensive and theoretically informed measures of socio-economic position. Second, we need more concerted attention to conceptualize and measure the effects of racism on health.

\section{Improved measurement of social position}

Much prior research on the role of socioeconomic status in racial differences in health has used only one indicator of SES in a given study. Currently, the extent to which limitations in the measurement of SES accounts for the failure of SES to account completely for racial differences in health is not known. In particular, the contribution of multiple indicators of SES to racial differences in health is unclear. In addition, health researchers have recently emphasized the importance of including in epidemiologic studies theoretically driven measures of social class to characterize fully the relationship between social stratification and health (Krieger et al., 1993; Krieger, Williams, \& Moss, 1997). Current measures give greater emphasis to Weberian notions of social stratification than to the Marxist emphasis on relationship to the system of production. The Marxist view of class emphasizes that social classes are collectivities defined in relationship to other social classes on the basis of opposing interests. The distribution of power and resources vary across social classes but social classes are not primarily gradational in the extent to which they possess particular attributes. Wright (1985) indicates that social classes in contemporary society are rooted in the complex intersection of exploitation based on the ownership of capital assets, organizational assets and the possession of skill or credential assets. From a comprehensive battery of survey items to measure social class, Wright (1997) has recently identified a smaller subset of items that capture most of the variation in the concept. 


\section{The experience of racial bias and health}

A growing number of researchers have emphasized that racism is a neglected but central societal force that adversely affects the health of racial and ethnic minority populations (Cooper, 1993; Cooper, Steinhauer, Miller, David, \& Shatzkin, 1981; King \& Williams, 1995; Krieger et al., 1993; Williams, 1996a; Williams et al., 1994). The term racism includes an ideology of superiority that categorizes and ranks various groups, negative attitudes and beliefs about outgroups and differential treatment of outgroups by individuals and societal institutions. The most profound impact of racism is at the level of societal institutions in shaping the socio-economic opportunities, mobility and life chances of racialized groups. The quality and quantity of a broad range of health-enhancing resources, including medical care, are differentially distributed by societal institutions, to members of discriminated against racial groups. Much of the observed racial differences in SES reflects the results of these processes.

In addition to discrimination at the societal level, stressful life experiences linked to race can also adversely impact the health of minority populations. Stress can affect racial differences in health in at least two ways. First, stress is not randomly distributed in the population. It is linked to social structure, and social status and social roles determine both the types and quantities of stress to which an individual is exposed (Pearlin, 1989; Williams \& House, 1991). The structural location of blacks in society would lead them to have higher levels of stress than whites. Second, the experience of specific incidents of racial bias can generate psychic distress and lead to alterations in physiological processes that can adversely affect health. There is growing attention to the pervasiveness and persistence of racial discrimination for African Americans (Cose, 1993; Essed, 1991; Feagin, 1991).

Descriptions of these experiences suggest that they capture important elements of stressful experiences that are known to be predictive of adverse changes in health. Critiques of the stress literature have also emphasized that the current approaches to the assessment of stress are not comprehensive and do not capture some of the stressful life experiences of poor populations in general and racial minority populations in particular (Aneshensel, 1992; Thoits, 1983). Several studies indicate that experiences of discrimination based on race or ethnicity can adversely affect physical and mental health (Amaro, Russo, \& Johnson, 1987; Jackson et al., 1996; James, La Croix, Kleinbaum, \& Strogatz, 1984; Krieger, 1990; Salgado de Snyder, 1987; Williams \& Chung, in press). And one recent study found that racial discrimination not only is associated with systolic and diastolic blood pressure but accounts for a part of the association between race and blood pressure (Krieger \& Sidney, 1996).

Studies of the relationship between racial discrimination and health are still in their infancy and are subject to several limitations. First, although experiences of racial bias are complex and multidimensional (McNeilly et al., 1996), the conceptualization of discrimination has been limited in many of the studies to date such that the phenomenon has not been comprehensively assessed. Some studies, for example, have utilized only a single-item global measure of discrimination. Second, studies have typically focused only on major experiences of discrimination. In contrast, Essed (1991) emphasizes that discrimination is a structured part of everyday experiences and includes not only major stressful life experiences but recurrent indignities and irritations in everyday situations.

Third, limited attention has been given to experiences of unfair treatment for the white population. It has been emphasized that the major forces affecting the health of minority populations are important societal factors that affect the health of the larger society on a smaller scale and in less intensive a manner (Cooper et al., 1981; Jackson \& Inglehart, 1995). Consistent with this perspective some evidence indicates that the experience of unfair treatment, irrespective of race or ethnicity, may have negative consequences for health (Harburg et al., 1973). It is likely that African Americans will have more frequent and more intense experiences of unfair treatment than will whites, but perceived racial or ethnic bias, including perceptions of reverse discrimination, could also adversely affect the health of whites (Jackson, Williams, \& Torres, in press). Thus, studying the impact of experiences of unfair treatment on 
the health of black and white adults can highlight the extent to which patterns observed among blacks are unique.

This article analyses probability sample data from a large metropolitan area in the United States to examine the extent to which multiple measures of social stratification combine with race-related stressful experiences and more general measures of stress to affect health and explain racial/ethnic variations in health status. Prior research has tended to test these major classes of explanatory factors in isolation or in pairs. We have multiple measures within each class of factors and can examine how each class performs in relation to the others. This model of competing explanations has rarely been tested in the literature with the breadth and range of measures in this article.

The goals of this study are to assess the extent to which: (1) levels of general stress and racerelated stress vary by race; (2) indicators of socio-economic status and social class, considered singly and in combination, can account for black-white differences in physical and mental health; and (3) race-related stressors and general measures of stress can account for racial differences in health. We hypothesize that multiple measures of SES will account for a large part of racial differences in health. We also hypothesize that the comprehensive assessment of stress, both race-related and general sources of stress, will play incremental roles in accounting for reported racial differences in health.

\section{Methods}

\section{Sample}

The data for our analyses come from the 1995 Detroit Area Study (DAS). The DAS is a multistage area probability sample consisting of 1139 adult respondents, 18 years of age and older, residing in Wayne, Oakland and Macomb counties in Michigan, including the city of Detroit. Face-to-face interviews were completed between April and October 1995 by University of Michigan graduate students in a researchtraining practicum in survey research and professional interviewers from the Survey Research Center. The response rate was 70 percent. Race was measured by respondent self-identification. Blacks were oversampled and the final sample included 520 whites; 586 blacks; and 33 Asians,
Native Americans and Hispanics. All of the analyses reported in this article use only the black and white respondents.

\section{Measures and analyses}

All intervally scaled measures were coded in the direction of the variable name so that a high score reflected a high value of the variable name. Four measures of health status are used as dependent variables in the analyses. Self-rated ill health is a widely used general indicator of health status that is strongly related to mortality and other objective measures of health. It captures a respondent's overall assessment of health as 'excellent, very good, good, fair, or poor'. Psychological distress (Cronbach's alpha $=.86$ ) sums the frequency with which respondents felt sad, nervous, restless or fidgety, hopeless, worthless and that everything was an effort in the past 30 days. This particular measure was recently developed as part of a project that used modern Item Response Theory methods to identify an optimal short-form scale of non-specific psychological distress that was equally reliable across subsamples of the US population defined by age, sex, race/ethnicity, education, marital status and region (Kessler \& Mroczek, 1994, 1995). Bed-days, a measure of physical incapacitation, is a count of the number of days in the last month that the respondent was totally unable to work or carry out normal activities because of both physical health problems and emotional distress. Measures of psychological well-being attempt to assess an individual's overall perception of the quality of life. Our well-being measure combines each respondent's assessment of overall life satisfaction on a 5-point scale ranging from 'completely satisfied' to 'not at all satisfied' with the respondent's agreement with the statement: 'My life is full of joy and satisfaction' on a 4-point agreedisagree scale.

Age (in years) and gender $(1=$ female, $0=$ male) are sociodemographic control variables used in the analyses. Race was assessed by respondent self-report. It was coded as a dummy variable in the regression analyses $(1=$ blacks, $0=$ whites). Income and education are two measures of socio-economic status. Our income measure captures total household income in the previous year. Since income is a highly skewed variable, we used its logarithm. Because the 
meaning of a given level of income is related to the number of persons in the analyses, household size is included in the analyses whenever we analyse income. Household size is a count of the number of persons living in the household ranging from 1 to 6 or more. Education is divided into four categories that capture meaningful differences in educational credentials: $0-11$ years, 12 years, $13-15$ years, and 16 or more years. Education is used as a set of dummy variables in the regression analyses with 16 years or more as an omitted category.

Following Wright (1997) we classified respondents into social classes based on their pattern of responses to three questions:

1. 'Do you hold a managerial position at your place of employment?'

2. 'As an official part of your job, do you supervise the work of other employees, have responsibility for or tell other employees what work to do?'

3. 'At your work place, do you participate in making decisions about such things as the products or services offered, the total number of people employed, budgets, and so forth?'

Respondents who gave an affirmative response to all three questions were categorized as Managers $(n=224)$, while respondents who answered 'no' to all three questions were categorized as Workers $(n=411)$. Those who answered 'yes' or 'no' to the managerial question, 'yes' to the supervisory question and 'no' to the decision-making question are Supervisors $(n=171)$. However, our preliminary analyses revealed two additional categories that did not perfectly fit Wright's (1997) coding instructions. There were 154 'special workers': persons who answered 'no' to the supervisory and managerial questions but 'yes' to the decision-making question. There were also 102 'special supervisors': persons who answered 'no' to the managerial question, 'yes' to the supervisory question, but also 'yes' to the decision-making question. These five categories were utilized in exploratory analyses and we found that for our health outcomes, the 'worker' and 'special worker' categories, as well as the 'supervisor' and 'special supervisor' categories related similarly to the dependent variables. Therefore, we collapsed the categories and our final social-class measure has three categories: Worker $(n=565)$;
Supervisor $(n=273)$; and Manager $(n=224)$. Manager was treated as the omitted category in our regression analyses.

Two measures of race-related stress were utilized: discrimination and everyday discrimination. Unlike prior research, both of them were framed in the context of unfairness instead of in the context of race. Discrimination, a measure of major experiences of unfair treatment, is a count of three items:

1. 'Do you think you have ever been unfairly fired or denied promotion?'

2. 'For unfair reasons, do you think you have ever not been hired for a job?'

3. 'Do you think you have ever been unfairly stopped, searched, questioned, physically threatened or abused by the police?'

Our second measure, everyday discrimination, attempts to measure more chronic, routine, and relatively minor experiences of unfair treatment (Essed, 1991). It sums nine items that capture the frequency of the following experiences in the day-to-day lives of respondents: being treated with less courtesy than others; less respect than others; receiving poorer service than others in restaurants or stores; people acting as if you are not smart; they are better than you; they are afraid of you; they think you are dishonest; being called names or insulted; and being threatened or harassed (Cronbach's alpha = $.88)$.

Three general indicators of stress were also utilized. Chronic stress is a count of problems in the last month or so, with aging parents, spouse or partner, children, hassles at work and balancing work and family demands. Financial stress is measured by the respondent's assessment of the difficulty of meeting the family's monthly payments on a 5-point scale ranging from extremely difficult to not difficult at all. Life events is a count of nine possible experiences in the year prior to the interview. These include serious illness or injury, physical attack or assault, robbery or burglary, involuntary retirement, unemployment, a move to a worse residence or neighborhood, serious financial problems, interracial arguments or conflicts and death of a loved one.

The data were weighted to take into account differential probabilities of selection and to adjust the demographics of the sample to that of 
the area from which it was drawn. Simple descriptive analyses are used to present racial differences in the distribution of responses on SES, social class and stress. Ordinary least squares regression is used to estimate the size and statistical significance of the associations between our independent variables and health status.

\section{Results}

\section{Racial differences in SES and stress}

Table 1 presents the distributions of SES, social class and stress by race. Racial differences for all of the variables are significant at $p \leq .05$. Blacks have significantly higher scores than have whites on all variables in Table 1 except

Table 1. Race differences in the distribution of SES, social class and stress, means and percentages $(\mathrm{P})$

\begin{tabular}{|c|c|c|}
\hline & Blacks & Whites \\
\hline \multicolumn{3}{|l|}{ Socio-economic status } \\
\hline \multicolumn{3}{|l|}{ 1. Education (P) } \\
\hline a. $0-11$ yrs & 19.5 & 11.8 \\
\hline b. $12 \mathrm{yrs}$ & 31.9 & 30.4 \\
\hline c. $13-15 \mathrm{yrs}$ & 33.0 & 28.4 \\
\hline d. $16+$ yrs & 15.5 & 29.4 \\
\hline \multicolumn{3}{|l|}{ 2. Household income (P) } \\
\hline a. $\$ 0-9,999$ & 21.0 & 5.7 \\
\hline b. $\$ 10,000-\$ 29,999$ & 32.4 & 23.4 \\
\hline c. $\$ 30,000-\$ 59,999$ & 30.3 & 29.7 \\
\hline d. $\$ 60,000+$ & 16.3 & 41.2 \\
\hline 3. Household Size & 3.098 & 2.88 \\
\hline \multicolumn{3}{|l|}{ Social Class } \\
\hline \multicolumn{3}{|l|}{ 4. Social class $(\mathrm{P})$} \\
\hline a. Worker & 60.6 & 50.8 \\
\hline b. Supervisor & 26.5 & 25.5 \\
\hline c. Manager & 12.9 & 23.7 \\
\hline \multicolumn{3}{|l|}{ Race-related stress } \\
\hline \multicolumn{3}{|l|}{ 5. Discrimination $(\mathrm{P})$} \\
\hline a. None & 37.7 & 63.8 \\
\hline b. One event & 28.7 & 24.8 \\
\hline c. Two events & 22.1 & 9.8 \\
\hline d. Three events & 11.5 & 1.6 \\
\hline 6. Everyday discrimination & 2.099 & 1.71 \\
\hline \multicolumn{3}{|l|}{ General stress } \\
\hline 7. Chronic stress & 0.90 & 1.07 \\
\hline 8. Financial stress & 1.996 & 1.65 \\
\hline 9. Life events & 1.561 & 0.85 \\
\hline
\end{tabular}

the measure of chronic stress, where the mean for whites exceeds that for blacks. In the interest of clarity, we present percentage differences for meaningful categories of several of the variables. Levels of educational attainment vary by race, with the racial gap being especially pronounced at both ends of the educational distribution. Blacks are 1.6 times more likely than whites to have completed less than 12 years of education. There are no racial differences in the middle of the educational distribution (highschool graduation, some college), but whites are almost twice as likely as African Americans to have graduated from college. A similar pattern is evident for income. Blacks are almost four times as likely as whites to have a total annual income of less than $\$ 10,000$ (21\% vs $6 \%$ ) and are 1.4 times more likely than whites to be in the $\$ 10,000-\$ 29,999$ range. Equivalent percentages of blacks and whites are in the middle-income category $(\$ 30,000-\$ 59,999)$, but whites are 2.5 times more likely than blacks to have incomes over $\$ 60,000$ (41\% vs $16 \%)$. The lower average income of blacks provides for households that on average are significantly larger than those of whites. The racial distribution by social class follows the familiar pattern noted for education and income. Blacks are more likely than whites to be in the worker category (61\% vs $51 \%)$, equivalent numbers of blacks and whites are supervisors, but whites are almost twice as likely as blacks to be managers ( $24 \%$ vs $13 \%$ ).

Table 1 also shows differences between the races for the stress measures. Blacks are more likely than whites to report major experiences of discrimination in employment and in contact with the police. Only slightly more African Americans than whites (29\% vs $25 \%$ ) report one discriminatory event, but blacks are twice as likely to report two discriminatory experiences and seven times more likely to report three experiences. Blacks also have significantly higher scores on the chronic ongoing indicators of everyday discrimination, although the magnitude of the racial gap is not as large as for the major experiences of discrimination. There is a significant racial difference on chronic stress, with whites having higher levels of chronic stress than blacks. Levels of financial stress are significantly higher for blacks than for whites and the average score on the life-events scale for blacks is almost twice that of whites. 


\section{Race, SES and health}

Table 2 presents the findings for the association among race, SES and social class, with selfreported ill health and bed-days. Five regression models are presented for each of the health outcomes. The first model shows the association between race and health, adjusted for the demographic variables (age and gender). The next three models consider the impact of education, income and occupation, considered singly, while the final model enters the three measures of social position simultaneously. As expected, Table 2 shows that blacks report higher levels of poor health than do whites. This difference is significant, after adjusted for age and gender and is reduced by almost 25 percent when adjusted for education. The race effect is dramatically reduced when economic status is considered but it remains significant. Controlling for income reduced the coefficient for race by 56 percent from the first model. Social class is unrelated to variations in self-reported health and makes no contribution to explaining racial differences in health. When all three measures of social position are considered in Model $\mathrm{V}$, the racial difference is reduced by more than half, to marginal significance. When considered simultaneously, the association of both education and income with health is reduced from the earlier models, but they both remain significant predictors of variations in self-reported ill health.

A similar pattern is evident for bed-days. Blacks report higher levels of bed-days than do whites. People with a high-school education or less report higher levels of bed-days than do college graduates. However, adjusting for education only minimally reduces the racial difference on this health income. Income is inversely related to bed-days and adjustment for income reduces the coefficient for race by 55 percent, to marginal significance. Similar to the pattern observed for self-reported ill health, social class is unrelated to bed-days and plays no role in accounting for racial differences. The final

Table 2. Unstandardized regression coefficients for the association of race, SES and social class to selfreported ill health and bed-days for blacks and whites, Detroit area study (DAS)

\begin{tabular}{|c|c|c|c|c|c|c|c|c|c|c|}
\hline & \multicolumn{5}{|c|}{ Self-reported ill health } & \multicolumn{5}{|c|}{ Bed-days } \\
\hline & $I$ & II & $I I I$ & $I V$ & $V$ & $I$ & $I I$ & $I I I$ & $I V$ & $V$ \\
\hline 1. Race (black) & $.315^{* *}$ & $.241 * *$ & $.140 *$ & $.303 * *$ & $.131 \dagger$ & $.194 * *$ & $.170^{* *}$ & $.087 \dagger$ & $.186^{* *}$ & $.086 \dagger$ \\
\hline 2. Age & $.018 * *$ & $.018 * *$ & $.019 * *$ & $.019 * *$ & $.018 * *$ & $.005 * *$ & $.004 * *$ & $.004 * *$ & $.005^{* *}$ & $.004 * *$ \\
\hline 3. Sex (female) & .061 & .030 & -.012 & .046 & -.014 & .034 & .029 & -.013 & .025 & -.008 \\
\hline $\begin{array}{l}\text { 4. Education } \\
\text { a. } 0-11 \mathrm{yrs} \\
\text { b. } 12 \mathrm{yrs} \\
\text { c. } 13-15 \mathrm{yrs} \\
\text { d. } 16+\mathrm{yrs} \\
\text { (omitted) }\end{array}$ & & $\begin{array}{l}.682 * * \\
.386 * * \\
.315 * *\end{array}$ & & & $\begin{array}{l}.485 * * \\
.286 * * \\
.266 * *\end{array}$ & & $\begin{array}{l}.257 * * \\
.123 * \\
.048\end{array}$ & & & $\begin{array}{r}.099 \\
.027 \\
-.011\end{array}$ \\
\hline $\begin{array}{l}\text { 5. Household } \\
\text { income (log) }\end{array}$ & & & $-.630 * *$ & & $-.503 * *$ & & & $-.394 * *$ & & $-.365^{* *}$ \\
\hline $\begin{array}{l}\text { 6. Household } \\
\text { size }\end{array}$ & & & .048 & & .037 & & & .010 & & .006 \\
\hline $\begin{array}{l}\text { 7. Social Class } \\
\text { a. Worker } \\
\text { b. Supervisor } \\
\text { c. Manager } \\
\text { (omitted) }\end{array}$ & & & & $\begin{array}{l}.117 \\
.029\end{array}$ & $\begin{array}{l}-.083 \\
-.138\end{array}$ & & & & $\begin{array}{l}.093 \\
.077\end{array}$ & $\begin{array}{r}-.002 \\
.036\end{array}$ \\
\hline Constant & 1.494 & 1.252 & 4.285 & 1.433 & 3.614 & -.070 & -.125 & 1.761 & -.130 & 1.627 \\
\hline $\mathrm{R}^{2}$ & .118 & .149 & .170 & .120 & .189 & .028 & .041 & .072 & .030 & .075 \\
\hline
\end{tabular}

$\dagger=p \leq .10 ; *=p \leq .05 ; * *=p \leq .01$ 
model indicates that the racial difference in beddays remains marginally significant when adjusted for education, income and social class. Instructively, unlike the pattern observed for self-reported ill health, educational differences disappear when adjusted for income. Thus, income emerges as the strongest predictor or variations in bed-days.

Table 3 presents similar models for the two measures of mental health status-psychological well-being and psychological distress. The table shows that although levels of psychological well-being are unrelated to age and gender, African Americans report lower levels of well-being than whites do. Education is positively related to well-being. College graduates enjoy higher levels of psychological wellbeing than do people with less education. Moreover, the education-well-being association fits the pattern of a linear graded relationship. Persons in each educational category report lower levels of well-being than do the category just above them. The consideration of education reduces racial differences in well-being by more than 20 percent. The third model reveals that there is also a strong positive relationship between income and well-being and an inverse relationship between well-being and household size. Moreover, consideration of economic status reduces racial differences in well-being by 75 percent to non-significance. Similar to the pattern observed earlier, social class is unrelated to variations in well-being. The fifth model shows that when income and education are considered simultaneously, the association of each with well-being is reduced, but both of them remain significantly related to the health outcome.

The findings for psychological distress are also presented in Table 3. Although the coefficient for race is in the direction of higher levels of psychological distress for blacks vs whites, the coefficient is not significant in the first model that also includes the demographic vari-

Table 3. Unstandardized regression coefficients for the association of race, SES and social class to well-being and psychological distress for blacks and whites, Detroit area study (DAS)

\begin{tabular}{|c|c|c|c|c|c|c|c|c|c|c|}
\hline & & & Well-being & & & & Psycl & hological di & listress & \\
\hline & $I$ & II & III & IV & V & $I$ & II & III & IV & V \\
\hline 1. Race (black) & $-.331 * *$ & $-.262 * *$ & -.083 & $-.320 * *$ & -.083 & .493 & .244 & -.117 & .467 & -.114 \\
\hline 2. Age & .003 & $.004 \dagger$ & .003 & .003 & .003 & $-.014 \dagger$ & $-.020 *$ & -.007 & $-.014 \dagger$ & -.013 \\
\hline 3. Sex (female) & .115 & $.139 \dagger$ & $.210^{*}$ & .130 & $.202^{*}$ & $.828^{* * *}$ & $.776^{* *}$ & $.579 \dagger$ & $.809 * *$ & $.684^{*}$ \\
\hline $\begin{array}{l}\text { 4. Education } \\
\text { a. } 0-11 \mathrm{yrs} \\
\text { b. } 12 \mathrm{yrs} \\
\text { c. } 13-15 \mathrm{yrs} \\
\text { d. } 16+\mathrm{yrs} \\
\text { (omitted) }\end{array}$ & & $\begin{array}{l}-.654^{* *} \\
-.441^{* *} \\
-.228^{*}\end{array}$ & & & $\begin{array}{l}-.355^{*} \\
-.277^{*} \\
-.144\end{array}$ & & $\begin{array}{l}2.608 * * \\
1.282 * * \\
.335\end{array}$ & & & $\begin{array}{c}1.944 * * \\
.817 * \\
.075\end{array}$ \\
\hline $\begin{array}{l}\text { 5. Household } \\
\text { income (log) }\end{array}$ & & & $.879 * *$ & & $.782 * *$ & & & $-.2169 * *$ & & $-1.666^{* *}$ \\
\hline $\begin{array}{l}\text { 6. Household } \\
\text { size }\end{array}$ & & & $-.076^{*}$ & & $-.067^{*}$ & & & $.398 * *$ & & $.334 * *$ \\
\hline $\begin{array}{l}\text { 7. Social class } \\
\text { a. Worker } \\
\text { b. Supervisor } \\
\text { c. Manager } \\
\text { (omitted) }\end{array}$ & & & & $\begin{array}{l}-.117 \\
-.007\end{array}$ & $\begin{array}{l}.109 \\
.183\end{array}$ & & & & $\begin{array}{l}.201 \\
.980 *\end{array}$ & $\begin{array}{r}-.473 \\
.479\end{array}$ \\
\hline Constant & 5.782 & 6.006 & 1.919 & 5.838 & 2.382 & 6.840 & 6.314 & 15.474 & 6.476 & 13.166 \\
\hline $\mathrm{R}^{2}$ & .014 & .039 & .071 & .016 & .079 & .012 & .043 & .046 & .018 & .067 \\
\hline
\end{tabular}

$\dagger=p \leq .10 ; *=p \leq .05 ; * *=p \leq .01$ 
ables. As expected, women report higher levels of psychological distress than men do. However, education is related to psychological distress, with persons with 12 years of education or less having higher levels of distress than college graduates had. Income and household size are also related to psychological distress. Distress decreases with increasing levels of income, but increases with the number of persons in the household. Social class is related to psychological distress, with supervisors reporting higher levels of distress than managers did. This relationship between social class and distress is reduced to non-significance when adjusted for income and education in the fifth model; however, both of these variables are somewhat reduced but remain significantly related to distress in this final model that considers the three social status measures together.

\section{Race, SES, stress and health}

Table 4 shows the incremental contribution of stress to understanding variations in levels of self-reported ill health and bed-days. Three hierarchical regression models are presented for each outcome. The first shows the relationship between race and health, adjusted for the demographic factors, as well as, education, income and social class. The second model considers race-related stressors and the third adds general measures of stress. While major experiences of discrimination are unrelated to self-assessed ill health, everyday discrimination is positively related to ill health. There is a small but significant increase in the explained variance from Model I to Model II. Moreover, the adjustment for the discrimination measures reduces the race coefficient by almost 40 percent, to nonsignificance. Thus, race-related stressors make a small incremental contribution to accounting for SES differences in self-reported ill health. The third model adds the three general indicators of stress and consideration of these variables produces a significant increase in the $\mathrm{R}^{2}$. Chronic stress is unrelated to selfreported ill health, but both financial stress and

Table 4. Unstandardized regression coefficients for the association of race, SES, social class, race-related stress and general stress to self-reported ill health and bed-days for blacks and whites, Detroit area study (DAS) ${ }^{1}$

\begin{tabular}{|c|c|c|c|c|c|c|}
\hline & \multicolumn{3}{|c|}{ Self-reported ill health } & \multicolumn{3}{|c|}{ Bed-days } \\
\hline & $I$ & II & III & $I$ & $I I$ & III \\
\hline 1. Race (black) & $.131 \dagger$ & .080 & .063 & $.086 \dagger$ & .037 & .004 \\
\hline $\begin{array}{l}\text { 2. Education } \\
\text { a. } 0-11 \mathrm{yrs} \\
\text { b. } 12 \mathrm{yrs} \\
\text { c. } 13-15 \mathrm{yrs} \\
\text { d. } 16+\text { yrs (omitted) }\end{array}$ & $\begin{array}{l}.485^{* *} \\
.286^{* *} \\
.266^{* *}\end{array}$ & $\begin{array}{l}.488^{* *} \\
.280^{* *} \\
.257^{* *}\end{array}$ & $\begin{array}{l}.445 * * \\
.287 * * \\
.236 * *\end{array}$ & $\begin{array}{r}.099 \\
.027 \\
-.011\end{array}$ & $\begin{array}{r}.104 \\
.022 \\
-.017\end{array}$ & $\begin{array}{r}.054 \\
.022 \\
-.043\end{array}$ \\
\hline 3. Household income $(\log )$ & $-.503 * *$ & $-.501 * *$ & $-.353 * *$ & $-.365^{* *}$ & $-.361 * *$ & $-.276 * *$ \\
\hline 4. Household size & .037 & $.039 \dagger$ & .012 & .006 & .008 & -.009 \\
\hline $\begin{array}{l}\text { Race-related stress } \\
\text { 5. Discrimination }\end{array}$ & & .022 & -.030 & & .014 & -.029 \\
\hline 6. Everyday discrimination & & $.108^{*}$ & .047 & & $.118^{* *}$ & $.079 *$ \\
\hline $\begin{array}{l}\text { General stress } \\
\text { 7. Chronic stress }\end{array}$ & & & .014 & & & .011 \\
\hline 8. Financial stress & & & $.099 * *$ & & & .031 \\
\hline 9. Life events & & & $.125 * *$ & & & $.126 * *$ \\
\hline $\begin{array}{l}\text { Constant } \\
\mathrm{R}^{2} \\
\text { Net } \mathrm{R}^{2}\end{array}$ & $\begin{array}{l}3.614 \\
.189 \\
-\end{array}$ & $\begin{array}{l}3.307 \\
.194 \\
.005^{*}\end{array}$ & $\begin{array}{l}2.533 \\
.226 \\
.030^{* *}\end{array}$ & $\begin{array}{c}1.627 \\
.075 \\
-\end{array}$ & $\begin{array}{l}1.297 \\
.086 \\
.011 * *\end{array}$ & $\begin{array}{l}.850 \\
.131 \\
.041 * *\end{array}$ \\
\hline
\end{tabular}

$\dagger=p \leq .10 ; *=p \leq .05 ; * *=p \leq .01$

${ }^{1}$ Adjusted for age, gender and social class 
major life events are positively related to ill health. That is, higher levels of stress are generally related with poorer health status. The coefficient for everyday discrimination is no longer associated with ill health once adjusted for the other measures of stress. For selfreported health, educational differentials are virtually unchanged when adjusted for stress. In contrast, adjustment for general measures of stress reduces the association between income and self-reported health by 30 percent.

Similar to the findings for self-reported illhealth major experiences of discrimination are unrelated to bed-days, while everyday discrimination is positively related. Adjustment for race-related stress also reduces the marginally significant relationship between race and beddays by almost 60 percent to non-significance. The relationship between everyday discrimination and bed-days is reduced by over 30 percent but remains significant when controlled for general indicators of stress. Of the three general indicators, only life events is positively related to bed-days. Both classes of stress variables produce a significant increase in the explained variance with the general stress variables having a larger impact. Similar to the pattern observed for self-reported ill health, consideration of stress, especially general measures of stress, reduces the association between income and bed-days by almost 25 percent from the first model. In sum, for both of the outcomes in Table 4, the consideration of stress makes an incremental contribution and, in combination with SES, completely accounts for racial differences in these health outcomes.

Table 5 shows the relationship among race, SES and stress for psychological well-being and psychological distress. It was noted earlier that racial differences in well-being were completely accounted for when adjusted for income, while race was unrelated to psychological distress. At the same time, it was of interest to note the relationship between stress and these indicators of mental health status. Models similar to those in Table 4 are presented for each of the mental

Table 5. Unstandardized regression coefficients for the association of race, SES, social class, race-related stress and general stress to well-being and psychological distress for blacks and whites, Detroit area study (DAS) ${ }^{1}$

\begin{tabular}{|c|c|c|c|c|c|c|}
\hline & \multicolumn{3}{|c|}{ Well-being } & \multicolumn{3}{|c|}{ Psychological distress } \\
\hline & $I$ & II & III & $I$ & II & III \\
\hline 1. Race (black) & -.083 & $.199 \dagger$ & .141 & -.114 & $-1.083^{* *}$ & $-.830^{*}$ \\
\hline $\begin{array}{l}\text { 2. Education } \\
\text { a. } 0-11 \mathrm{yrs} \\
\text { b. } 12 \mathrm{yrs} \\
\text { c. } 13-15 \mathrm{yrs} \\
\text { d. } 16+\text { yrs (omitted) }\end{array}$ & $\begin{array}{l}-.355^{*} \\
-.277^{*} \\
-.144\end{array}$ & $\begin{array}{l}-.368^{*} \\
-.248^{*} \\
-.096\end{array}$ & $\begin{array}{l}-.374 * * \\
-.322 * * \\
-.101\end{array}$ & $\begin{array}{c}1.944 * * \\
.817 * \\
.075\end{array}$ & $\begin{array}{c}2.021 * * \\
.659 \dagger \\
-.044\end{array}$ & $\begin{array}{c}2.154^{* *} \\
.967 * \\
.021\end{array}$ \\
\hline 3. Household income $(\log )$ & $.782 * *$ & $.762 * *$ & $.575^{* *}$ & $-1.666^{* *}$ & $-.550 * *$ & $-1.085^{* *}$ \\
\hline 4. Household size & $-.067 *$ & $-.080^{*}$ & -.003 & $.334 * *$ & $.355^{* *}$ & .090 \\
\hline $\begin{array}{l}\text { Race-related stress } \\
\text { 5. Discrimination }\end{array}$ & & $-.150 * *$ & -.066 & & -.046 & $-.331 \dagger$ \\
\hline 6. Everyday discrimination & & $-.550 * *$ & $-.391 * *$ & & $2.818^{* *}$ & $2.215^{* *}$ \\
\hline $\begin{array}{l}\text { General stress } \\
\text { 7. Chronic stress }\end{array}$ & & & $-.181 * *$ & & & $.805^{* *}$ \\
\hline 8. Financial stress & & & $-.213 * *$ & & & $.557 * *$ \\
\hline 9. Life events & & & $-.094 *$ & & & $.304 *$ \\
\hline $\begin{array}{l}\text { Constant } \\
\mathrm{R}^{2} \\
\text { Net } \mathrm{R}^{2}\end{array}$ & $\begin{array}{r}2.382 \\
.079 \\
-\end{array}$ & $\begin{array}{l}4.027 \\
.157 \\
.078^{* *}\end{array}$ & $\begin{array}{l}5.016 \\
.213 \\
.055^{* *}\end{array}$ & $\begin{array}{r}13.166 \\
.067 \\
-\quad\end{array}$ & $\begin{array}{l}5.699 \\
.185 \\
.118^{* *}\end{array}$ & $\begin{array}{l}3.323 \\
.241 \\
.056^{* *}\end{array}$ \\
\hline
\end{tabular}

$\dagger=p \leq .10 ; *=p \leq .05 ; * *=p \leq .01$

${ }^{1}$ Adjusted for age, gender and social class 
health outcomes in Table 5. Both of the measures of race-related stress are inversely related to psychological well-being. Persons who report higher levels of major experiences of discrimination and everyday discrimination report lower levels of psychological well-being. Consideration of race-related stress produces a substantial increase in the explained variance.

Interestingly, when the two measures of racerelated stress are included in the model, the association between race and psychological well-being becomes positive and marginally significant. That is, there is a tendency for blacks to report higher levels of psychological well-being when race-related stressors are taken into account. This marginally significant positive association between race and psychological well-being in Model II is reduced by one-third to non-significance when adjusted for the general measures of stress in Model III. Chronic stress, financial stress and life events are all inversely related to psychological well-being and this set of stress measures significantly increases the variance explained in well-being. When controlled for the general measures of stress, the coefficient for everyday discrimination is reduced by almost one-third, but remains significant, while the coefficient for major experiences of discrimination is reduced to nonsignificance. It is also instructive to note that the relationship between education and well-being is not markedly changed when adjusted for stress. In contrast, the association between income and well-being is minimally reduced when adjusted for race-related stress but reduced by almost one-fourth (but remained significant) when general measures of stress are considered. Thus, income appears to be more closely linked to stress-related conditions of life than does education.

The findings for psychological distress are similar to those observed for well-being. There is a strong positive relationship between everyday discrimination and psychological distress. Persons who report that they frequently experienced everyday discrimination also report higher levels of psychological distress. Major experiences of discrimination are unrelated to psychological distress, but consideration of racerelated stress makes an incremental contribution of 12 percent to the explained variance. Importantly, once the coefficients for race-related stress are included in the model the relationship between race and psychological distress become significant. That is, when experiences of unfairness are controlled for blacks and whites, blacks report significantly lower levels of psychological distress than whites do. In addition, adjustment for race-related stress reduces the relationship between income and psychological distress by two-thirds. An interesting pattern is evident for education. When adjusted for racerelated stress, the coefficient for the lowest levels of education becomes slightly stronger while that of the second lowest level becomes considerably weaker. The final model for psychological distress reveals that all of the indicators of general stress (chronic stress, financial stress and life events) are positively related to psychological distress. The association between everyday discrimination is reduced only modestly and remained significant when adjusted for general measures of stress.

\section{Differential vulnerability}

The data in Table 5 are consistent with the notion that race-related stress may have a more adverse impact on the mental health functioning of whites as compared to blacks. When adjusted for race-related stress, the coefficient for the association between race and well-being changes from a non-significant -.08 to a marginally significant $.20(p=.07)$. Similarly, the association between race and psychological distress increased almost tenfold from a nonsignificant -.11 to a significant $-1.08(p<.01)$ when race-related stress is added to the model. That is, for both measures of mental health status, blacks tend to experience better health than whites do when adjusted for race-related stress. We systematically evaluated the hypothesis of racial variations in vulnerability to stress for all of our measures of health status.

In analyses not shown, we created multiplicative interaction terms between race and each of our measures of race-related and general stress. We added these interaction terms singly and in combination to a model that included the demographic controls, SES, social class and stress. We found few significant interactions. No interactions were evident for psychological distress and self-reported ill health. There was a significant interaction between race and everyday discrimination for psychological well-being. 
This measure of race-related stress was more strongly related to well-being for whites as compared to blacks. In contrast, both financial stress and life events significantly interacted with race in predicting bed-days such that both of these stressors adversely affected blacks more than whites. More careful research is needed to identify the conditions under which the impact of stress is exacerbated or minimized for particular subgroups in the population.

\section{Discussion}

This study has several limitations. First, the data are cross-sectional and provide no basis for causal directionality. At the same time, the findings are consistent with a large body of work that suggests that social conditions are important determinants of variations in health. High levels of stress and low socio-economic status are two important social factors that have been identified in prior research as pathogenic. Second, the measures of discrimination utilized in this study are based on respondent self-report. This criticism is frequently raised about the measurement of racial discrimination, although it applies to much of the measurement of stress more generally. Considerable evidence suggests that discrimination is ubiquitous in US society (Cose, 1993; Feagin, 1991; Gardner, 1995). The stressfulness of a life experience is determined, in part, by the meaning it has for the individual which is importantly linked to that individual's personal and social history. Thus, a respondent's perception and appraisal of a life experience is a critical component of the experience of stress. Nonetheless, strategies that have been developed to improve the measurement of stress (Cohen, Kessler, \& Gordon, 1995), also apply to the assessment of discrimination.

Finally, this study focused only on blacks and whites. There is considerably more racial and ethnic variation in the United States that is also importantly linked to variations in SES and health (Williams, 1996b). Recent studies find that other minority groups, such as Asians (Kim \& Lewis, 1994) and Hispanics (Telles \& Murgia, 1990) also experience discrimination. Future research must explore the health consequences of discrimination for the various groups that make up the racial and ethnic diversity of the US population.
At the same time, this study provides important additional evidence of the importance of the social environment in understanding racial variations in health. We found racial differences in the expected direction for three of the four health outcomes considered. African Americans reported lower levels of psychological wellbeing; higher rates of self-reported ill health; and more bed-days than whites did. Education and especially income were importantly related to all of the health outcomes examined and played a major role in explaining racial differences in health. Social class, as measured in this study, was generally unrelated to health and played no role in racial differences in disease. This pattern is inconsistent with that of a recent study that found that social class, as measured at both the household and community level, predicted variations in health (Krieger, 1991). More research attention needs to be given to the appropriate operationalization of the construct of social class in health-related research. Our analyses also found that race-related stress, as well as general measures of stress, are generally adversely related to health and make an incremental contribution to explaining racial differences in health. Race-related stress was more strongly related to our indicators of mental health than it was to physical health.

Our measures of SES were not interchangeable. Race-related stress was linked more strongly to income than to education. In addition, experiences of discrimination accounted for part of the association between income and health. Income was also linked more strongly to health status than to education. Krieger and Fee (1994) have reported a similar pattern in national data for at least some measures of health status. Although the reasons for these differences are not clear, they have clear policy implications. Income is probably the component of SES that is most amenable to change through governmental policies, such as tax credits or direct income supplementation, and a small body of evidence suggests that changes in household income can enhance health, even in the absence of interventions in medical care (Williams \& Collins, 1995). Different indicators of SES capture different aspects of the pathway by which social structure affects health. More research attention must be given to the appropriate conceptualization and measurement of 
SES and the identification of the mechanisms and processes by which they affect health (Krieger et al., 1997).

For both measures of mental health status, the mental health of blacks tended to exceed that of whites once we adjusted for race-related stress. This pattern is consistent with the notion that these stressful experiences may affect the health of whites more adversely than that of blacks. A recent review noted that for a number of child and infant health outcomes, although blacks are more exposed to adverse risk factors, these factors have a larger impact on the health status of whites than that of blacks (Williams \& Collins, 1995). Kessler (1979) documented a similar pattern for the relationship between stressful life events and psychological distress for nonwhites (mainly blacks) and low SES persons. Both of these economically disadvantaged groups were more exposed to stress. However, compared to nonwhites and low SES individuals, comparable stressful events more adversely affected the mental health of whites and high SES persons, respectively. Kessler (1979) suggested some possible reasons for this relative advantage.

First, due to earlier exposure and/or more frequent exposure to adversity, African Americans could become more accustomed to dealing with stress, such that a new stressful experience has less of an impact. Second, compared to whites, African Americans may respond to stress with greater emotional flexibility (that is, emotional expression), which may facilitate recovery. In addition, African Americans may have greater access than that of whites to other coping resources, such as religious involvement, that some have argued may importantly reduce the negative effects of stress (Williams, 1994).

The hypothesis that blacks cope better with stress than whites do could shed light on an important paradox in the literature. Compared to whites, African Americans have higher rates of disease and death for virtually all measures of physical health (U.S. Department of Health and Human Services, 1985), but they also have equivalent or lower rates of psychiatric illness (Kessler et al., 1994; Robins \& Regier, 1991) and lower rates of suicide (Griffith \& Bell, 1989). If blacks cope better with stress, there may be a consequential trade-off. Although effective coping may shield African Americans from the psychological sequelae of stress, the cumulative effects of high exposure to stress may take a heavy physical toll and leave them more vulnerable to a broad range of physical ailments (cf. Geronimus, 1992). This issue deserves careful research attention.

Our analyses also emphasize that understanding racial differences in health importantly requires an appropriate theoretical framework. Because we conceptualized race as not reflecting biological distinctiveness, we examined other factors (socio-economic status and stress) that are linked to the social situation of racial groups. A different understanding of race could have led to a search for genetic and biological differences. At the same time, our findings document that the associations among race, racism, SES and health are complex. Racism is a part of the structure of society and arguably the most profound health impact of racism is at the level of societal institutions (Williams, 1996a). Racial differences in SES reflect some of the economic manifestations of racial discrimination. Cooper and David (1986) argue that since SES is an intermediate variable in the causal pathway between race and health, adjusting racial differences for SES is a form of overcontrol and should not be used in health studies. Although we agree that SES is not technically a confounder of racial differences in health, it is an important intermediate factor. Our approach suggests that analytic control can be usefully employed for non-confounders. We control for these intermediate factors, not to eliminate bias but to facilitate an understanding of the processes that link race (a marker of social privilege or economic disadvantage) to health.

Although the measurement of socio-economic position and discrimination in this study was more comprehensive than typical, neither of these constructs was measured perfectly in this study. More careful conceptual work and thoughtful empirical analyses are necessary to take into account the complex ways in which economic and non-economic forms of discrimination relate to each other and combine with other risk factors to affect health. Instructively, the measure of everyday discrimination was a more consistent and robust predictor of health status than the measure of major experiences with discrimination. This is consistent with the larger stress literature which finds that stressors 
that are persistent and repeated may more adversely affect health than those that are episodic and time limited (Lepore, 1995). Our analyses also indicate that how SES and discrimination combine to affect health importantly depends on the health outcome under consideration. This highlights the need for more research that focuses on identifying under what conditions specific aspects of social structure are related to particular health outcomes.

In an era of waning public support and government commitment to making the needed investment to improve the social and economic conditions of the most vulnerable populations in the USA, our analyses document that race matters a lot in terms of health. Moreover, the sources of racial disparities are not unknown, individual or obscure. They can be traced to inequalities that have been created and maintained by the economic, legal and political structures of society. These systems, and not individual beliefs and behavior, are the fundamental causes of racial and socio-economic inequalities in health (Williams, 1990; Williams, in press). Eliminating these health disparities will thus require changes in the fundamental social systems in society.

\section{References}

Amaro, H., Russo, N. F., \& Johnson, J. (1987).

Family and work predictors of psychological wellbeing among Hispanic women professionals. Psychology of Women Quarterly, 11, 505-521.

Anderson, N. B., McNeilly, M., \& Myers, H. (1991). Autonomic reactivity and hypertension in blacks: A review and proposed model. Ethnicity and Disease, 1, 154-170.

Aneshensel, C. S. (1992). Social stress: Theory and research. American Sociological Review, 18, 15-38.

Cohen, S., Kessler, R. C., \& Gordon, L. U. (1995). Measuring stress: A guide for health and social scientists. New York: Oxford University Press.

Cooper, R. S. (1993). Health and the social status of blacks in the United States. Annals of Epidemiology, 3, 137-144.

Cooper, R. S., \& David, R. (1986). The biological concept of race and its application to public health and epidemiology. Journal of Health and Politics, Policy and Law, 11, 97-116.

Cooper, R. S., Steinhauer, M., Miller, W., David, R., \& Schatzkin, A. (1981). Racism, society, and disease: An exploration of the social and biological mechanisms of differential mortality. International Journal of Health Services, 11(3), 389-414.

Cose, E. (1993). The rage of a privileged class. New York: HarperCollins.

Danziger, S., \& Gottschalk, P. (Eds.) (1993). Uneven tides: Rising inequality in America. New York: Russell Sage.

Essed, P. (1991). Understanding everyday racism. Newbury Park, CA: Sage.

Feagin, J. R. (1991). The continuing significance of race: Antiblack discrimination in public places. American Sociological Review, 56, 101-116.

Gardner, C. B. (1995). Passing by: Gender and public harassment. Berkeley: University of California Press.

Geronimus, A. T. (1992). The weathering hypothesis and the health of African-American women and infants. Ethnicity and Disease, 2, 207-221.

Gould, S. J. (1977). Why we should not name human races: A biological view. In S. J. Gould (Ed.), Ever since Darwin (pp. 231-236). New York: Norton.

Griffith, E., \& Bell, C. (1989). Recent trends in suicide and homicide among blacks. Journal of the American Medical Association, 262, 2265-2269.

Harburg, E., Erfurt, J., Chape, C., Havenstein, L., Schull, W., \& Schork, M. A. (1973).

Socioecological stressor areas and black-white blood pressure: Detroit. Journal of Chronic Disease, 26, 595-611.

Hummer, R. A. (1996). Black-white differences in health and mortality: A review and conceptual model. Sociological Quarterly, 37(1), 105-125.

Jackson, J. S., Brown, T. N., Williams, D. R., Torres, M., Sellers, S. L., \& Brown, K. (1996). Racism and the physical and mental health status of African Americans: A thirteen year national panel study. Ethnicity and Disease, 6(1,2), 132-147.

Jackson, J. S., \& Inglehart, M. R. (1995). Reverberation theory: Stress and racism in hierarchically structured communities. In S. E. Hobfoll \& M. DeVries (Eds.), Extreme stress and communities: Impact and interventions, pp. 353-373. Dordrecht: Kluwer Academic.

Jackson, J. S., Williams, D. R., \& Torres, M. (in press). Racial discrimination, stress, action orientation and physical and psychological health. National Institute of Mental Health.

James, S. A., LaCroix, A. Z., Kleinbaum, D. G., \& Strogatz, D. S. (1984). John Henryism and blood pressure differences among black men. II. The role of occupational stressors. Journal of Behavioral Medicine, 7, 259-275.

Karoly, L. A. (1992). The trend in inequality among families, individuals, and workers in the United States: A twenty-five year perspective. Santa Monica, CA: Rand. 
Kessler, R. C. (1979). Stress, social status, and psychological distress. Journal of Health and Social Behavior, 20, 259-273.

Kessler, R. C., McGonagle, K. A., Zhao, S., Nelson, C. B., Hughers, M., Eshleman, S., Wittchen, H., \& Kendler, K. S. (1994). Lifetime and 12-month prevalence of DSM-III-R psychiatric disorders in the United States. Archives of General Psychiatry, $51,8-19$.

Kessler, R. C., \& Mroczek, D. (1994). Scoring the UM-CIDI short forms. Ann Arbor: Survey

Research Center, University of Michigan.

Kessler, R. C., \& Mroczek, D. (1995). Measuring the effects of medical interventions. Medical Care, 33, AS109-AS119.

Kim, P. S., \& Lewis, G. B. (1994). Americans in the public service: Success, diversity, and discrimination. Public Administration Review, 54, 285-290.

King, G., \& Williams, D. R. (1995). Race and health: A multi-dimensional approach to African American Health. In B. C. Amick, S. Levine, D. C. Walsh, \& A. Tarlov (Eds.), Society and health (pp. 93-130). New York: Oxford University Press.

Krieger, N. (1987). Shades of difference: Theoretical underpinnings of the medical controversy on black/white differences in the United States, 1830-1870. International Journal of Health Services, 17, 259-278.

Krieger, N. (1990). Racial and gender discrimination: Risk factors for high blood pressure? Social Science and Medicine, 30(12), 1273-1281.

Krieger, N. (1991). Women and social class: A methodological study comparing individual, household, and census measures as predictors of black/white differences in reproductive history. Journal of Epidemiology and Community Health, 45, 35-42.

Krieger, N., \& Fee, E. (1994). Social class: The missing link in U.S. health data. International Journal of Health Services, 24, 25-44.

Krieger, N., Rowley, D. L., Herman, A. A., Avery, B., \& Phillips, M. T. (1993). Racism, sexism, and social class: Implications for studies of health, disease, and well-being. American Journal of Preventive Medicine, 9 (Suppl. 6 ), 82-122.

Krieger, N., \& Sidney, S. (1996). Racial discrimination and blood pressure: the CARDIA study of young black and white women and men. American Journal of Public Health, 86(10), 1370-1378.

Krieger, N., Williams, D. R., \& Moss, N. E. (1997). Measuring social class in U.S. public health research: Concepts, methodologies, and guidelines. Annual Review of Public Health, 18, 341-378.

Lepore, S. J. (1995). Measurement of chronic stressors. In S. C. Cohen, R. C. Kessler, \& L. U. Gordon (Eds.), Measuring stress: A guide for health and social scientists (pp. 102-120). New York: Oxford University Press.

Lewontin, R. C. (1972). The apportionment of human diversity. In Th. Dobzhansky, M. K. Hecht, \& W. C. Steere (Eds.), Evolutionary biology (Vol. 6, pp. 381-386). New York: Appleton-CenturyCrofts.

Lillie-Blanton, M., Parsons, P. E., Gayle, H., \& Dievler, A. (1996). Racial differences in health: Not just black and white, but shades of gray. Annual Review of Public Health, 17, 411-448.

Massey, D. S., \& Denton, N. A. (1993). American apartheid: Segregation and the making of the underclass. Cambridge, MA: Harvard University Press.

McNeilly, M. D., Anderson, N. B., Armstead, C. A., Clark, R., Corbett, M., Robinson, E. L., Pieper, C. F., \& Lepisto, E. M. (1996). The perceived racism scale: A multidimensional assessment of the experience of white racism among African Americans. Ethnicity and Disease, 6(1,2), 154-166.

National Center for Health Statistics (1993). Health, United States, 1992 and healthy people review. Washington, DC: U.S. Government Printing Office. National Center for Health Statistics (1994). Vital statistics of the United States, 1990. Vol. II, Mortality Part A. Hyattsville, MD: Public Health Service.

Omi, M., \& Winant, H. (1986). Racial formation in the United States: From the 1960s to the 1980s. New York: Routledge.

Pearlin, L. I. (1989). The sociological study of stress. Journal of Health and Social Behavior, 30(3), 241-256.

Robins, L. N., \& Regier, D. A. (1991). Psychiatric disorders in America: The epidemiologic catchment area study. New York: Free Press.

Salgado de Snyder, V. N. (1987). Factors associated with acculturative stress and depressive symptomatology among married Mexican immigrant women. Psychology of Women Quarterly, 11, 475-488.

Smith, J. P., \& Welch, F. R. (1989). Black economic progress after Myrdal. Journal of Economic Literature, 27, 519-564.

Telles, E. E., \& Murgia, E. (1990). Phenotypic discrimination and income differences among Mexican Americans. Social Science Quarterly, 71, 682-697.

Thoits, P. A. (1983). Dimensions of life events that influence psychological distress: An evaluation and synthesis of the literature. In H. B. Kaplan (Ed.), Psychosocial research: Trends in theory and research (pp. 33-103). New York: Academic. 
U.S. Department of Health and Human Services (1985). Report of the Secretary's task force on black and minority health. Washington, DC: U.S. Government Printing Office.

Vega, W. A., \& Rumbaut, R. G. (1991). Ethnic minorities and mental health. Annual Review of Sociology, 17, 351-383.

Williams, D. R. (1990). Socioeconomic differentials in health: A review and redirection. Social Psychology Quarterly, 3, 81-99.

Williams, D. R. (1994). The measurement of religion in epidemiologic studies: Problems and prospects. In J. S. Levin (Ed.), Religion in aging and health: Theoretical foundations and methodological frontiers (pp. 125-148). Thousand Oaks, CA: Sage.

Williams, D. R. (1996a). Racism and health: A research agenda. Ethnicity and Disease, 6, 1-6.

Williams, D. R. (1996b). Race, ethnicity, and socioeconomic status: Measurement and methodological issues. International Journal of Health Services, 26(3), 483-505.

Williams, D. R. (in press). Race and health: Basic questions, emerging directions. Annals of Epidemiology.
Williams, D. R., \& Chung, A-M. (in press). Racism and health. In R. Gibson \& J. S. Jackson (Eds.), Health in black America. Thousand Oaks, CA: Sage.

Williams, D. R., \& Collins, C. (1995).

Socioeconomic and racial differences in health. Annual Review of Sociology, 21, 349-386.

Williams, D. R., \& House, J. S. (1991). Stress, social support, control and coping: A social epidemiologic view. In B. Badura \& I. Kickbusch (Eds.), Health promotion research: Towards a new social epidemiology. Copenhagen: World Health Organization.

Williams, D. R., Lavizzo-Mourey, R., \& Warren, R. C. (1994). The concept of race and health status in America. Public Health Reports, 109, 26-41.

Witzig, R. (1996). The medicalization of race: Scientific legitimization of a flawed social construct. Annals of Internal Medicine, 125, 675-679.

Wright, E. O. (1985). Classes. London: Verso. Wright, E. O. (1997). Class counts: Comparative studies in class analysis. New York: Cambridge University Press. 